\title{
'Every Breath You Take I'Il Be Watching You': Measuring Exercise Kinetics during 6-Min Walking Test in COPD
}

\author{
Andriana I. Papaioannou ${ }^{a}$ Stylianos E. Orfanos ${ }^{b}$ \\ a Second Respiratory Medicine Department and becond Department of Critical Care, Attikon University Hospital, \\ University of Athens Medical School, Athens, Greece
}

Exercise limitation is one of the major characteristics of everyday life for COPD patients and has been shown to be related to increased exacerbation risk [1], poor health-related quality of life and increased mortality [24]. The main symptoms that limit exercise in most COPD patients are dyspnea and fatigue, both of which result from ventilatory parameters, pulmonary gas exchange abnormalities, peripheral muscle dysfunction, cardiac decompensation, or any combination of the above [5].

An analysis of the factors which limit exercise tolerance in COPD may uncover hidden exercise-related issues, including hypoxemia, dysrhythmias and cardiac ischemia [5]. Cardiovascular deconditioning is very common in COPD patients and a substantial amount of the increase in exercise tolerance following cardiopulmonary rehabilitation also reflects improvements in cardiovascular function, besides the well-established muscular enforcement $[6,7]$. Clarification of the underlying cause of exercise intolerance in COPD would ideally be the major determinant of therapeutic interventions.

In a recent issue of Respiration van Gestel et al. [8] used a portable cardiopulmonary monitoring device in order to quantify oxygen exchange kinetics during the 6-min walking test (6MWT). With this setting, the authors were able to record in a 'breath by breath' manner several pa-

\section{KARGER}

E-Mail karger@karger.com

www.karger.com/res rameters, including pulse rate, oxygen saturation $\left(\mathrm{SpO}_{2}\right)$, oxygen uptake $\left(\mathrm{VO}_{2}\right)$, carbon dioxide output $\left(\mathrm{VCO}_{2}\right)$, total volume, and breathing frequency, and to quantify $\mathrm{VO}_{2}$ kinetics in real time. After carefully excluding patients with inaccurate mean response time (MRT) estimation, the authors observed that patients with more severe airflow limitation (patients with severe and very severe COPD) had worse corrected work MRT (wMRT) and oxygen uptake at steady state $\left(\mathrm{VO}_{2 s s}\right)$. The distance walked in $6 \mathrm{~min}(6 \mathrm{MWD})$ is used as the main outcome of the $6 \mathrm{MWT}$ [9]. In the study of van Gestel et al., wMRT was associated both with the $6 \mathrm{MWD}$ and the $\mathrm{VO}_{2 s s}$, providing evidence that the result of such a simple test, combined with the use of a portable device, may be used as a marker of exercise tolerance instead of the complicated and demanding cardiopulmonary exercise testing.

Although the 6MWT is mainly considered as a test of submaximal exercise testing [10], it is important to state that during the study over $80 \%$ of patients reached the criteria for maximal exercise. This observation is of great importance, since the results of the present study suggest that a simple 6MWT may reflect the overall exercise capacity in the majority of COPD patients, which can then be translated to important information regarding disease severity and outcomes. 
The great majority of patients in the study of van Gestel et al. [8] suffered from severe and very severe COPD (GOLD stages III and IV) and most of them experienced exercise limitations due to ventilatory factors and gas exchange. This is in accordance with previous data supporting the hypothesis that patients with severe airway obstruction usually experience exercise limitations due to intense dyspnea which is the result of an imbalance between ventilatory demands and capacity and, to a lesser extent, leg discomfort resulting from inadequate energy supply to locomotor muscles of the lower extremities [5]. The dynamic hyperinflation which occurs during exercise leads to respiratory discomfort and exercise limitations, which have also been observed in patients with moderate airway obstruction (GOLD stage II) [5].

Interestingly, only $12.5 \%$ of the study participants experienced cardiocirculatory limitation during exercise. However, the fact that wMRT is known to be mostly de- pendant on the rate of increase of pulmonary blood flow [11], combined with the association between wMRT and disease severity in the current study, probably supports the view that exercise tolerance in more severe COPD is also limited by cardiocirculatory parameters. This finding suggests that the optimal management of exercise limitation may need to include the optimization of the cardiocirculatory status of COPD patients. This needs to be addressed in future studies.

Overall, the quantification of $\mathrm{VO}_{2}$ kinetics in real time during $6 \mathrm{MWT}$ may be a simple but precise and thorough approach to evaluate the causes of exercise limitation in patients with COPD. Such interventions may lead to more targeted management of exercise limitation in COPD, involving effective bronchodilation, the optimization of cardiocirculatory status and/or the improvement of physical deconditioning, to the extent that each of these parameters needs to be refined.

\section{References}

1 Pitta F, Troosters T, Probst VS, Spruit MA, Decramer M, Gosselink R: Physical activity and hospitalization for exacerbation of COPD. Chest 2006;129:536-544.

2 Global Strategy for the Diagnosis, Management and Prevention of COPD. Global Initiative for Chronic Obstructive Lung Disease (GOLD) 2014. http://www.goldcopd.org (accessed July 26, 2014).

$\checkmark 3$ Jones PW: Activity limitation and quality of life in COPD. COPD 2007;4:273-278.

4 Garcia-Aymerich J, Lange P, Benet M, Schnohr P, Anto JM: Regular physical activity reduces hospital admission and mortality in chronic obstructive pulmonary disease: a population based cohort study. Thorax 2006; 61:772-778.
5 Vogiatzis I, Zakynthinos S: Factors limiting exercise tolerance in chronic lung diseases. Compr Physiol 2012:2:1779-1817.

6 Camillo CA, Laburu Vde M, Goncalves NS, Cavalheri V, Tomasi FP, Hernandes NA, Ramos D, Marquez Vanderlei LC, Cipulo Ramos EM, Probst VS, Pitta F: Improvement of heart rate variability after exercise training and its predictors in COPD. Respir Med 2011;105: 1054-1062.

7 Gale NS, Duckers JM, Enright S, Cockcroft JR, Shale DJ, Bolton CE: Does pulmonary rehabilitation address cardiovascular risk factors in patients with COPD? BMC Pulm Med 2011;11:20.

8 van Gestel AJR, Baty F, Rausch-Osthof A-K, Brutsche $\mathrm{MH}$ : Cardiopulmonary and gas exchange responses during the six-minute walk test in patients with chronic obstructive pulmonary disease. Respiration 2014;88:307-314.
19 ATS statement: guidelines for the six-minute walk test. Am J Respir Crit Care Med 2002; 166:111-117.

10 Troosters T, Vilaro J, Rabinovich R, Casas A, Barbera JA, Rodriguez-Roisin R, Roca J: Physiological responses to the 6-min walk test in patients with chronic obstructive pulmonary disease. Eur Respir J 2002;20:564-569.

11 Kemps HM, Schep G, Hoogsteen J, Thijssen EJ, De Vries WR, Zonderland M, Doevendans P: Oxygen uptake kinetics in chronic heart failure: clinical and physiological aspects. Neth Heart J 2009; 17:238-244. 